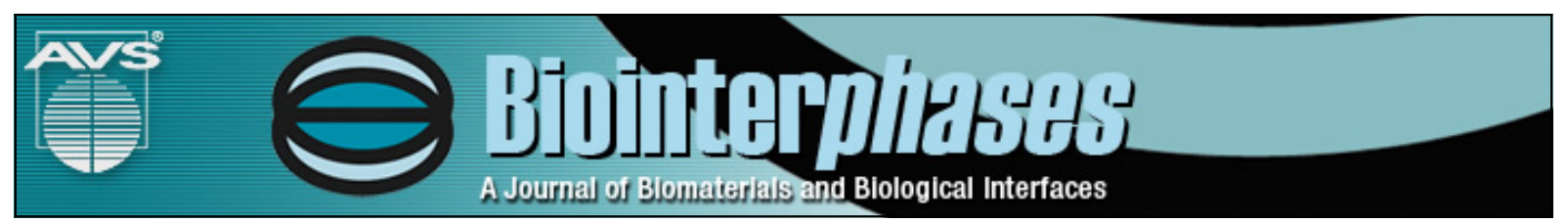

Comparative study of CW, nanosecond- and femtosecond-pulsed laser microcutting of AZ31 magnesium alloy stents

Ali Gökhan Demir and Barbara Previtali

Citation: Biointerphases 9, 029004 (2014); doi: 10.1116/1.4866589

View online: http://dx.doi.org/10.1116/1.4866589

View Table of Contents: http://scitation.aip.org/content/avs/journal/bip/9/2?ver=pdfcov

Published by the AVS: Science \& Technology of Materials, Interfaces, and Processing 


\title{
Comparative study of CW, nanosecond- and femtosecond-pulsed laser microcutting of AZ31 magnesium alloy stents
}

\author{
Ali Gökhan Demir ${ }^{\text {a) }}$ and Barbara Previtali ${ }^{\text {b) }}$ \\ Department of Mechanical Engineering, Politecnico di Milano, Via La Masa 1, 20156 Milan, Italy
}

(Received 9 January 2014; accepted 10 February 2014; published 24 February 2014)

\begin{abstract}
Magnesium alloys constitute an interesting solution for cardiovascular stents due to their biocompatibility and biodegradability in human body. Laser microcutting is the industrially accepted method for stent manufacturing. However, the laser-material interaction should be well investigated to control the quality characteristics of the microcutting process that concern the surface roughness, chemical composition, and microstructure of the final device. Despite the recent developments in industrial laser systems, a universal laser source that can be manipulated flexibly in terms of process parameters is far from reality. Therefore, comparative studies are required to demonstrate processing capabilities. In particular, the laser pulse duration is a key factor determining the processing regime. This work approaches the laser microcutting of AZ31 Mg alloy from the perspective of a comparative study to evaluate the machining capabilities in continuous wave $(\mathrm{CW})$, ns- and fs-pulsed regimes. Three industrial grade machining systems were compared to reach a benchmark in machining quality, productivity, and ease of postprocessing. The results confirmed that moving toward the ultrashort pulse domain the machining quality increases, but the need for postprocessing remains. The real advantage of ultrashort pulsed machining was the ease in postprocessing and maintaining geometrical integrity of the stent mesh after chemical etching. Resultantly, the overall production cycle time was shortest for fs-pulsed laser system, despite the fact that CW laser system provided highest cutting speed. (C) 2014 American Vacuum Society. [http://dx.doi.org/10.1116/1.4866589]
\end{abstract}

\section{BACKGROUND}

Biodegradability is an appealing property for minimally intrusive treatment of cardiovascular diseases especially in the case of infant patients. ${ }^{1}$ Both polymeric and metallic materials have been used as biodegradable stent materials. The metallic stent materials offer advantages in terms of better scaffolding and mechanical resistance. Moreover, they provide a shorter degradation time than polymeric stents. ${ }^{2}$ Concerning metallic biodegradable materials, the main choices have been pure iron and magnesium alloys. ${ }^{1-4}$ Being already present in human body, $\mathrm{Mg}$ is highly biocompatible but is characterized by low corrosion resistance in body fluids. Possible options to slow down the degradation rate of $\mathrm{Mg}$ alloys are (1) use of different alloying elements, ${ }^{5-7}$ (2) refining crystallographic structure, ${ }^{8,9}$ (3) use of coatings or physical surface treatments, ${ }^{10}$ and (4) optimization of the stent mesh. ${ }^{11,12}$ All of these aspects are viable if only adequate manufacturing steps are employed to realize the stent that maintains the geometric tolerances and required surface quality.

Laser microcutting is the most common method used for generating the stent mesh on microtubes. The possibility of obtaining high precision cutting with small kerf widths and complex geometries in $3 \mathrm{D}$ are the main advantages of laser microcutting technology. Although the use of lasers is an industrially accepted solution for cutting of the stent mesh

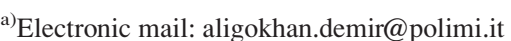

b) Author to whom correspondence should be addressed; electronic mail: barbara.previtali@polimi.it
}

on microtubes, the choice of appropriate laser system is a matter of open discussion for the specific manufacturing issue.

Laser cutting is often applied with continuous wave (CW) lasers that locally melt the material and eject it from opened kerf with the action of the process gas. ${ }^{13}$ This so called "melt and blow" technique is highly productive due to fast heat penetration, and relatively lower temperatures required for melting the material. This laser cutting modality received wider acceptance in stent making with the introduction of high brilliance active fiber laser sources ${ }^{14-17}$ to the point that nowadays is the common industrial practice. The low beam quality factor $\left(\mathrm{M}^{2}\right)$ and wavelength $(1 \mu \mathrm{m})$ of fiber lasers allowed much smaller spots compared to $\mathrm{CO}_{2}$ and $\mathrm{Nd}$ :YAG sources.

On the other hand, laser sources can be run in pulsed wave modality to release a defined quantity of energy in short durations of time. Both the pulse duration and shape determine the energy release into the material and alter the material removal mechanism. Despite the fact that these two parameters are crucially important for the outcome of the machining process, most of today's industrial laser systems do not possess capabilities of regulating them. The industrial laser systems that can be regulated in terms of these two parameters allow tuning in a limited range (e.g., regulation of pulse shape and duration only in ns regime). This is a direct consequence of the fact that different laser architectures are tailored to generate different pulse durations. From an industrial point of view, this means different laser sources for different pulse durations. This raises the long-going 
debate on the appropriate laser source for the given application. From the perspective of biomedical device manufacturing, the laser cutting process should yield high productivity and acceptable machining quality. The ultimate goal is to achieve laser machining conditions that eliminate any postprocessing.

The technical distinction between different pulse regimes depends on the changes regarding how the laser beam interacts with the material in different time scales. In particular, it is useful to consider the two temperatures belonging to the electron and the lattice subsystems $\left(\mathrm{T}_{\mathrm{e}}\right.$ and $\left.\mathrm{T}_{1}\right)$ to give a generic description to the occurring phenomenon. ${ }^{18-20}$ In this scheme two characteristic time scales can be defined as $\tau_{\mathrm{e}}$ and $\tau_{1}$, where $\tau_{\mathrm{e}}$ is the electron cooling time and $\tau_{1}$ is the lattice heating time, with $\tau_{\mathrm{e}} \ll \tau_{1}$.

For pulse durations $(\tau)$ lower than $100 \mathrm{fs}$, the ablation phenomenon occurs in the so called cold state, as the thermalization of first the electrons and later on the lattice is terminated while the matter is in condensed state. This condition represents $\tau \ll \tau_{\mathrm{e}}$, where an equilibrium between the lattice and the electrons is not present; thus, the material bulk is not heated. Increasing the pulse duration to around $10 \mathrm{ps}$, the so called hot ablation conditions are fulfilled, with $\tau_{\mathrm{e}} \ll \tau \ll \tau_{1}$. The electron and lattice temperatures tend to go closer to a thermal equilibrium, although thermal diffusivity of the lattice is negligible compared to that of electrons. Thus, the lattice temperature remains much smaller. Surface evaporation is still the dominant mechanism for material removal; however, melt generation inside the material is also present, which can degrade the machining quality. For pulse durations higher than $\sim 10 \mathrm{ps}$, thermal equilibrium between the lattice and the electrons forms, as the laser energy dissipates to the material bulk. The material removal is a mixture of vaporization from condensed matter, vaporization from molten phase, and melt expulsion. The generated molten layer, if not removed during the process, causes redeposited material layer around the ablation area that is regarded as dross or spatter.

The implication of afore described physical phenomenon is that the pulse duration is a factor that dominates the machining quality. Therefore, in the industrial practice, different laser sources are employed operating in different regimes, from long ( $\mathrm{ms}$ and $\mu \mathrm{s}$ durations) to short (ns durations) and ultrashort (fs and ps durations) pulses.

In literature, limited amount of work regarding laser microcutting of stents is reported, where CW emission, ${ }^{15}$ longpulsed, ${ }^{14,16,17,21,22}$ short-pulsed, ${ }^{23}$ and ultrashort pulsed ${ }^{24,25}$ sources are used on different materials. A comparison regarding the different machining domains appears to be absent to authors' knowledge. On the other hand, in the literature, manufacturing of $\mathrm{Mg}$ alloy biodegradable stents has been treated sparingly, ${ }^{23,26,27}$ despite the presence of clinical trials of commercial stents on animal models and human patients. ${ }^{28-30}$

This paper investigates laser microcutting of AZ31 alloy with three distinct laser cutting regimes for biodegradable magnesium stents. The used systems represent industrial solutions regarding $\mathrm{CW}$, ns- and fs-pulsed lasers. The studies had to be conducted in a nonparametric manner due to the intrinsically different process parameter window resulting from working with different laser sources. Moreover, it has been observed in previous studies that the process window of laser microcutting is limited. ${ }^{23}$ In a fixed pulse duration condition, indeed the margin of quality improvement is limited due to the geometrical restrictions of cutting a microtube. Therefore, it has been intended to report representative microcutting conditions that allow a comparison in pulse duration parameter space (i.e., continuous, ns, and fs). Accordingly, the system characteristics are thoroughly listed pointing out the main components that are essentially important for the machining quality. Laser microcutting is studied along with the chemical etching process as the finishing operation to remove dross and improve cut quality. Results regarding quality and productivity are compared both qualitatively and quantitatively.

\section{METHODS}

\section{A. Material}

AZ31 magnesium alloy in form of sheets and tubes was used to characterize the machining performance of the three laser systems. The $0.4 \mathrm{~mm}$ thick sheets were produced by cold rolling process and cut by the $\mathrm{CW}$ laser system. The microtubes of $2.5 \mathrm{~mm}$ diameter and $0.2 \mathrm{~mm}$ thickness were produced by extrusion and drawing and cut by the ns- and fs-pulsed systems. The surface characteristics of the two precursors, tube and sheet, represent the inherent effects of the manufacturing processes as depicted in Fig. 1. Table I reports the chemical composition of the AZ31 alloy obtained with the two different processing methods. Throughout the study, the novel stent mesh design of Politecnico di Milano was used as the cutting geometry. ${ }^{11}$ For the stent dimensions, see Fig. 2.

\section{B. Laser microcutting}

Three different laser systems based on active fiber architecture were used. The CW laser (YLR-150-750-QCW from IPG Photonics, Oxford, MA, USA) was based on the active fiber laser architecture. The $\mathrm{Yb}$ doped glass fiber is pumped with fiber coupled diodes. In particular, this system was composed of a single active fiber module, which allowed a high quality Gaussian beam $\left(\mathrm{M}^{2}=1\right)$. In addition to $\mathrm{CW}$ emission, the laser source can be modulated by fast switching electronics up to $1 \mathrm{kHz}$ frequency with $20 \%$ duty cycle. This way, long pulses in the range of $20 \mu \mathrm{s}-2 \mathrm{~ms}$ can be achieved. Within the comparative study, this laser source was employed in CW emission mode. The laser source generated a diverging laser beam at the end of the delivery fiber output. The beam was collimated with a $50 \mathrm{~mm}$ collimation lens and focused with a $80 \mathrm{~mm}$ focal lens inside a cutting head with $1.5 \mathrm{~mm}$ diameter nozzle (Fine Cutting Head FS from Precitec GmbH \& Co. KG, Gaggenau, Germany). For 2D cutting operations, the laser was integrated to linear axes that allowed workpiece movement in $\mathrm{X}-\mathrm{Y}$ plane and laser head movement in $\mathrm{Z}$ axis (AI-LM-15000-XY and 

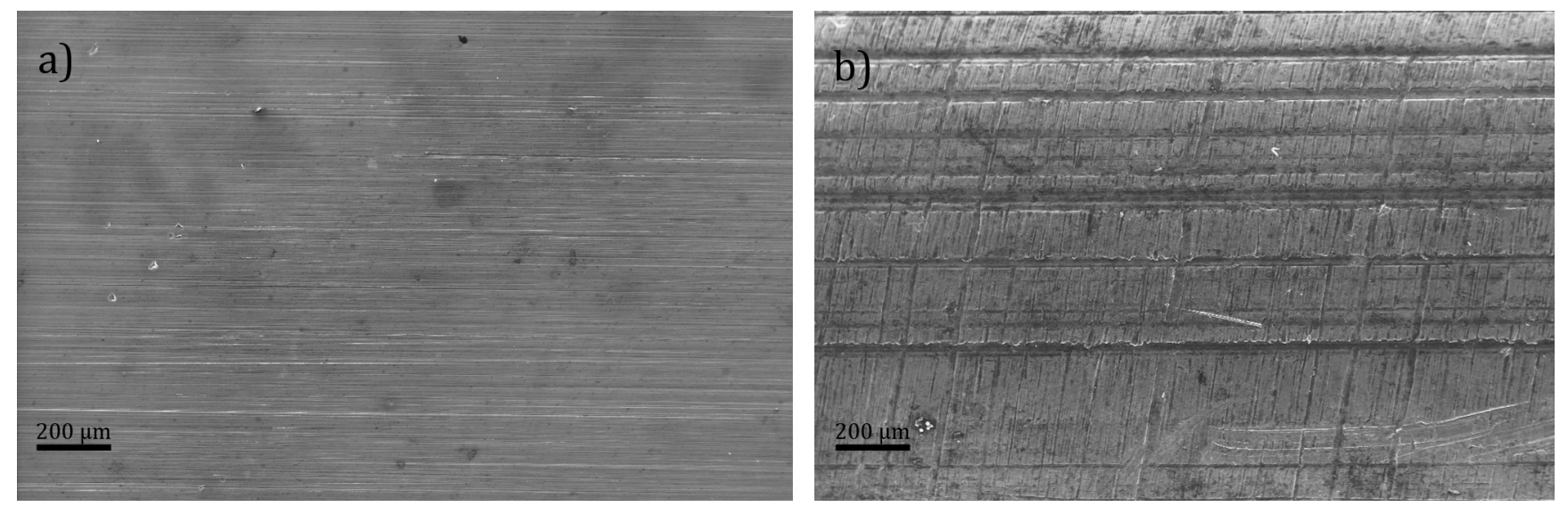

FIG. 1. Surface characteristics of the cut AZ31 sheets and tubes. (a) Cold rolled thin sheet with $0.4 \mathrm{~mm}$ thickness. A smooth surface with microvalleys in the rolling direction is visible. (b) Extruded and drawn microtube with $2.5 \mathrm{~mm}$ diameter and $0.2 \mathrm{~mm}$ thickness. Surface exhibits deeper grooves due to the manufacturing procedure.

AI-LM-5000-Z-CB from Alio Industries, Wheat Ridge, CO, USA).

The ns-pulsed laser was a Q-switched active fiber laser (YLP-1/100/50/50 from IPG Photonics, Oxford, MA, USA). The system used an optoacoustic Q-switch mechanism that produced pulse durations around $250 \mathrm{~ns}$ and pulse repetition rates between 20 and $80 \mathrm{kHz}$. The maximum pulse energy was $1 \mathrm{~mJ}$ with $9 \mathrm{~kW}$ peak power, whereas the maximum average output corresponded to $50 \mathrm{~W}$. The laser source had the delivery fiber coupled to an optical isolator and a collimation lens that provided a collimated beam output. The collimated beam was focused with a $60 \mathrm{~mm}$ focal lens housed in a cutting head with $0.5 \mathrm{~mm}$ diameter nozzle (Fine Kerf from Laser Mechanisms, Inc., Novi, MI, USA). Manipulation of microtubes was achieved via a linear and a rotational axis (ALS-130 and ACS-150 from Aerotech, Inc., Pittsburgh, PA, USA).

The fs-pulsed laser system was a turn-key product that incorporated both the laser source and workpiece manipulation systems on a single machine for laser microtube processing (StarFemto from Rofin-Baasel Lasertech, Starnberg, Germany). The laser system within the machine was based on a fiber optic chirped pulse amplification architecture. A mode-locked low power laser generates fs pulses at $1552 \mathrm{~nm}$ wavelength, which are first stretched to a longer duration, amplified in Er doped fiber amplifier, and then compressed back to fs duration. Until the pulse compression stage, the laser is all fiber based. A collimated beam is achieved at the source output and the beam is delivered in free-space into the cutting head that housed a $50 \mathrm{~mm}$ focal lens with $0.5 \mathrm{~mm}$ diameter nozzle. The laser source produced 800 fs pulses

TABLE I. Thickness and chemical composition of the AZ31 alloys used in the study.

\begin{tabular}{lccccc}
\hline \hline Alloy & Shape & $\begin{array}{c}\text { Thickness } \\
(\mathrm{mm})\end{array}$ & $\begin{array}{c}\mathrm{Al} \\
(\text { wt. \%) }\end{array}$ & $\begin{array}{c}\mathrm{Zn} \\
\text { (wt. \%) }\end{array}$ & $\begin{array}{c}\mathrm{Mg} \\
\text { (wt. \%) }\end{array}$ \\
\hline AZ31 & Sheet & 0.4 & 3.08 & 0.98 & Bal. \\
AZ31 & Tube $(\varnothing=2.5 \mathrm{~mm})$ & 0.2 & 3.88 & 0.82 & Bal. \\
\hline \hline
\end{tabular}

with $75 \mu \mathrm{J}$ maximum pulse energy. The maximum average output power was $6 \mathrm{~W}$, whereas the maximum peak power was $60 \mathrm{MW}$. Table II summarizes the characteristic parameters of the different laser systems used in the study.

\section{Chemical etching}

Chemical etching with ethanol- $\mathrm{HNO}_{3}$ solution was employed as a finishing operation after laser cutting operation. Etching was conducted with an interval of $10 \mathrm{~s}$ in immersion in the acidic solution and consecutively $10 \mathrm{~s}$ of immersion in water until the dross was removed completely from the cut stent mesh.

\section{Quality characterization}

The results were evaluated by optical stereo microscopy (MZ75 from Leica Microsystems, Wetzlar, Germany) and SEM (EVO-50, from Carl Zeiss, Oberkochen, Germany). Surface quality was characterized directly on the stent walls with an optical 3D profilometer based on focus variation microscopy (InfiniteFocus from Alicona Imaging $\mathrm{GmbH}$, Graz, Austria). The 3D profile acquisitions were made with a ring light source and $20 \times$ magnification. The estimated vertical and lateral resolutions were $0.27 \mu \mathrm{m}$ and $0.88 \mu \mathrm{m}$, respectively. Two acquisitions of the stent wall were made on different positions of the stent after laser cutting and after

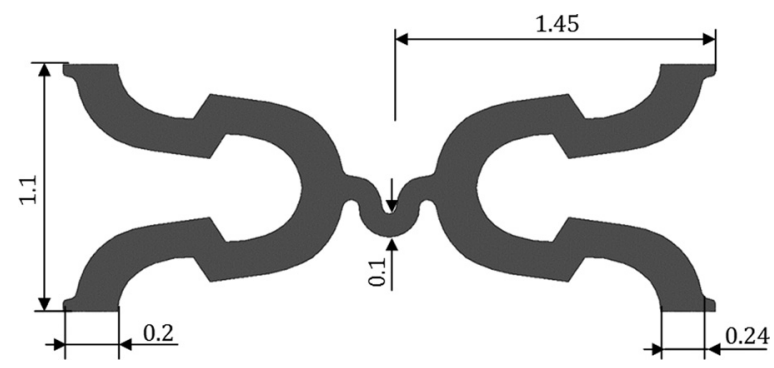

FIG. 2. Characteristic pattern of the novel stent mesh. The stent mesh consisted of five rings connected by curved links, presenting six peak-to-valley struts in the circular direction. 
TABLE II. Main characteristics of the different laser sources employed in the comparative study.

\begin{tabular}{|c|c|c|c|}
\hline Laser type & $\mathrm{CW}$ & ns-pulsed & fs-pulsed \\
\hline Brand and model & IPG YLR-150-750-QCW & IPG YLP-1/100/50/50 & Rofin StarFemto \\
\hline Architecture & Active fiber & Q-switched active fiber & Fiber optic chirped pulse amplification \\
\hline Active media & Yb:glass & Yb:glass & Er:glass \\
\hline Wavelength & $1070 \mathrm{~nm}$ & $1064 \mathrm{~nm}$ & $1552 \mathrm{~nm}$ \\
\hline Max. average power & $250 \mathrm{~W}$ & $50 \mathrm{~W}$ & $6 \mathrm{~W}$ \\
\hline Pulse duration & $20-2000 \mu \mathrm{s}$ & $250 \mathrm{~ns}$ & $800 \mathrm{fs}$ \\
\hline Pulse repetition rate & $0.01-1 \mathrm{kHz}$ & $20-80 \mathrm{kHz}$ & Single shot $-400 \mathrm{kHz}$ \\
\hline Max. pulse energy & $5 \mathrm{~J}$ & $1 \cdot 10^{-3} \mathrm{~J}$ & $75 \cdot 10^{-6} \mathrm{~J}$ \\
\hline Max. peak power & $250 \mathrm{~W}$ & $9 \cdot 10^{3} \mathrm{~W}$ & $60 \cdot 10^{6} \mathrm{~W}$ \\
\hline $\mathrm{M}^{2}$ & 1 & 1.7 & 1.3 \\
\hline Collimated beam diameter & $4.8 \mathrm{~mm}$ & $5.9 \mathrm{~mm}$ & $4.0 \mathrm{~mm}$ \\
\hline Focal lens & $80 \mathrm{~mm}$ & $60 \mathrm{~mm}$ & $50 \mathrm{~mm}$ \\
\hline Focused beam diameter & $22 \mu \mathrm{m}$ & $23 \mu \mathrm{m}$ & $32 \mu \mathrm{m}$ \\
\hline
\end{tabular}

chemical etching. The stent curvature was removed prior to the measurements with a second order polynomial to obtain a flat surface. On the flat surface, $400 \mu \mathrm{m}$ long profiles were taken on top, middle, and bottom positions, resulting in six measurement repetitions for each condition. Average surface roughness $R_{a}$, root mean squared of surface roughness $\mathrm{R}_{\mathrm{q}}$, and average distance between the highest peak and lowest valley $R_{z}$ were measured on the surface profiles. The cut-off frequency of the roughness measurements was $80 \mu \mathrm{m}$. The average value of the measurement repetitions was calculated for the stents after laser cutting and after chemical etching.

\section{RESULTS AND DISCUSSION}

Due to the completely different microcutting conditions, only one reference parameter set was determined for each laser system after preliminary investigations. The $\mathrm{CW}$ laser system used a parameter set that involved $150 \mathrm{~W}$ laser power with a high cutting speed of $20 \mathrm{~mm} / \mathrm{s}$. The laser focus was positioned at the bottom surface, allowing the highest irradiance to be achieved at the kerf exit. With CW cutting, high volumetric flow of gas is required to push the molten material from the open kerf. For this reason, larger nozzle diameters are preferred. As a matter of fact, the $\mathrm{CW}$ laser system used in this work was equipped with a larger nozzle compared to the ns- and fs-pulsed laser systems. This requires higher amount of gas consumption; therefore, the use of inert gases such as Ar becomes economically inconvenient. In industrial practice, very often $\mathrm{N}_{2}$ is preferred to Ar because it is less expensive and relatively inert. In order to operate close to precision cutting operations employed in the industrial practice, $\mathrm{N}_{2}$ was chosen as the shielding gas for $\mathrm{CW}$ cutting. On the other hand, 6 bar pressure was found to be suitable to cut the AZ31 alloy without causing defection on the cut material and reducing the amount of dross. Although $\mathrm{N}_{2}$ is characterized by worse shielding performance compared to Ar, no evidence of oxidation or surface nitriding was observed. The ns-pulsed laser system was chosen to operate with $7.5 \mathrm{~W}$ average power and $300 \mu \mathrm{J}$ pulse energy. The cutting speed was set as $2 \mathrm{~mm} / \mathrm{s}$. The cutting conditions represent an energy balance that allowed cutting through the material without generating damage on the other side of the tube. Such machining conditions were obtained with moderate pulse repetition rate $(25 \mathrm{kHz})$ and low cutting speed $(2 \mathrm{~mm} / \mathrm{s})$. Finally, for fs-pulsed microcutting, $5 \mathrm{~W}$ average power with $25 \mu \mathrm{J}$ was employed. The cutting speed was set as $5 \mathrm{~mm} / \mathrm{s}$, a value higher than the ns-pulsed system. This is due to higher pulse repetition rate $(200 \mathrm{kHz})$, as well as cleaner ablation mechanism provided by the ultrashort pulses. Material is removed from solid state, and heat is not dissipated to the material bulk. Pulsed wave microcutting based on ablation is much more sensitive to changes in material properties compared to $\mathrm{CW}$ microcutting. Because, ablation based processes rely on a so called ablation threshold. Local changes in the material composition may result in the change of the ablation threshold. During the microcutting operation, elevated local temperatures can induce oxide generation, which can increase the ablation threshold. Accordingly, $\mathrm{Ar}$ as an inert gas with better shielding performance was used in ns- and fs-pulsed cutting to avoid oxidation or other types of contamination that may halt cutting. The choice is also economically viable due to reduced gas use with smaller nozzles. For ns-pulsed cutting, 7 bar gas pressure was found suitable, whereas 6 bar was optimal for fs-pulsed cutting. The slight variation in the optimal gas pressure values can be attributed to difference in the cutting head and nozzle design. Table III gathers all the process parameters used in the comparative study.

Figure 3 shows the dross characteristics belonging to the different laser microcutting conditions, which render an immediate distinction between the possible cutting mechanisms. This distinction is evident especially in terms of the dross morphology. The CW laser generated high amount of dross at the exit side of the kerf, deposited from the molten phase of the material that is not effectively pushed away from the opened cut kerf. The height of the $\mathrm{CW}$ laser dross was measured to be $185 \mu \mathrm{m}$, which is comparable to the cut 
TABLE III. Reference laser microcutting and chemical etching conditions determined for the comparative study.

\begin{tabular}{|c|c|c|c|}
\hline Laser type & $\mathrm{CW}$ & ns-pulsed & fs-pulsed \\
\hline Average power, $\mathrm{P}_{\text {avg }}$ & $150 \mathrm{~W}$ & $7.5 \mathrm{~W}$ & $5 \mathrm{~W}$ \\
\hline Peak power, $\mathrm{P}_{\text {peak }}$ & $150 \mathrm{~W}$ & $2.5 \cdot 10^{3} \mathrm{~W}$ & $31 \cdot 10^{6} \mathrm{~W}$ \\
\hline Pulse energy, E & $\mathrm{n} / \mathrm{a}$ & $300 \mu \mathrm{J}$ & $25 \mu \mathrm{J}$ \\
\hline Pulse repetition rate, $\mathrm{PRR}$ & $\mathrm{n} / \mathrm{a}$ & $25 \mathrm{kHz}$ & $200 \mathrm{kHz}$ \\
\hline Cutting speed, v & $20 \mathrm{~mm} / \mathrm{s}$ & $2 \mathrm{~mm} / \mathrm{s}$ & $5 \mathrm{~mm} / \mathrm{s}$ \\
\hline Focal position, $\mathrm{f}$ & $-0.4 \mathrm{~mm}$ & $0 \mathrm{~mm}$ & $0 \mathrm{~mm}$ \\
\hline Gas type and pressure & $\mathrm{N}_{2}$ at 6 bar & Ar at $7 \mathrm{bar}$ & Ar at 6 bar \\
\hline Etchant proportion & $95 \%$ ethanol, $5 \% \mathrm{HNO}_{3}$ & $90 \%$ ethanol, $10 \% \mathrm{HNO}_{3}$ & $95 \%$ ethanol, $5 \% \mathrm{HNO}_{3}$ \\
\hline Etchant temperature & $25^{\circ} \mathrm{C}$ & $25^{\circ} \mathrm{C}$ & $25^{\circ} \mathrm{C}$ \\
\hline Etching duration & $180 \mathrm{~s}$ & $10 \mathrm{~s}$ & $10 \mathrm{~s}$ \\
\hline
\end{tabular}

thickness. The ns-pulsed laser generated dross in microgranular form deposited around the top side of the kerf, which suggests an explosive behavior during material removal. The dross height was measured to be around $85 \mu \mathrm{m}$ in this case. The material residue after fs-pulsed cutting was observed to be powderous. This shows that a material removal mechanism from the solid phase is more plausible as expressed in the theoretical analysis.

The transversal sections reported in Fig. 4 permit a better comprehension of the effect of the cutting conditions. The $\mathrm{CW}$ laser kerf is characterized by a small taper angle $\left(\theta=0.21^{\circ}\right)$ and straight walls. The kerf width both at top and bottom appears to be larger than the calculated laser spot diameter $\left(\mathrm{w}_{\text {top }}=50.1 \mu \mathrm{m}\right.$ and $\left.\mathrm{w}_{\text {bottom }}=26.8 \mu \mathrm{m}\right)$. This is due to material removal mechanism based on melting, since heat propagates also radially with respect to the laser beam axis. The ns-pulsed laser kerf was not possible to be observed before chemical etching due to the melt deposit; therefore, a section after chemical etching in $90 \%$ ethanol and $10 \%$ $\mathrm{HNO}_{3}$ solution for $10 \mathrm{~s}$ is reported in Fig. 4. The cleaned kerf exhibits larger taper $\left(\theta=0.43^{\circ}\right)$ and kerf width $\left(\mathrm{w}_{\text {top }}=54.8 \mu \mathrm{m}\right.$ and $\left.\mathrm{w}_{\text {bottom }}=28.9 \mu \mathrm{m}\right)$. Since the applied chemical etching was gentle and removed mainly dross, the observed kerf reasonably represents the laser cut conditions with slight enlargement of the kerf width. The kerf of fs-pulsed laser cut AZ31 tube shows a chamfered shape and taper similar to the one belonging to the ns-pulsed laser $\left(\theta=0.43^{\circ}\right)$. Toward the top of the kerf, the taper appears to be larger. As a matter of fact the kerf width is much larger than the calculated spot diameter on top and much smaller in the bottom $\left(\mathrm{w}_{\text {top }}=41.8 \mu \mathrm{m}\right.$ and $\left.\mathrm{w}_{\text {bottom }}=10.3 \mu \mathrm{m}\right)$. This can be attributed to the deflection of the beam by the ablation plasma, which is situated at the top of the cut kerf. As the machining propagates deeper in the material, the enlargement effect reduces. Since the ablation plume expands to low pressure front at the top of the cut edge, it is presumable that it does not penetrate into the closed kerf after a certain point due to increasing pressure drop. After the end of the chamfered zone, a reduced size of laser beam penetrates into the material, which generates the thinner section. These observations are in agreement with the literature regarding the effects of plasma on the micromachining quality with ultrashort pulses. ${ }^{31,32}$ Sun and Longtin reported that the use of inert gas improved drilling quality on $\mathrm{Cu}$ with fs pulses compared to drilling air by reducing plasma defocusing. ${ }^{31}$ However, their results show taper even under inert gas conditions. Li et al. studied the plasma characteristics in laser micromachining of stainless steel with fs pulses. ${ }^{32}$ They experimentally showed similar irregularities in the cut kerf when the focal position due to plasma defocusing effect, as well as analytically calculating the fluence profile of the laser beam under the plasma defocusing influence. Table IV summarizes all the kerf geometrical characteristics of the different laser systems.

In Fig. 5, stent meshes generated with the different laser sources are presented. In all machining conditions, the stent
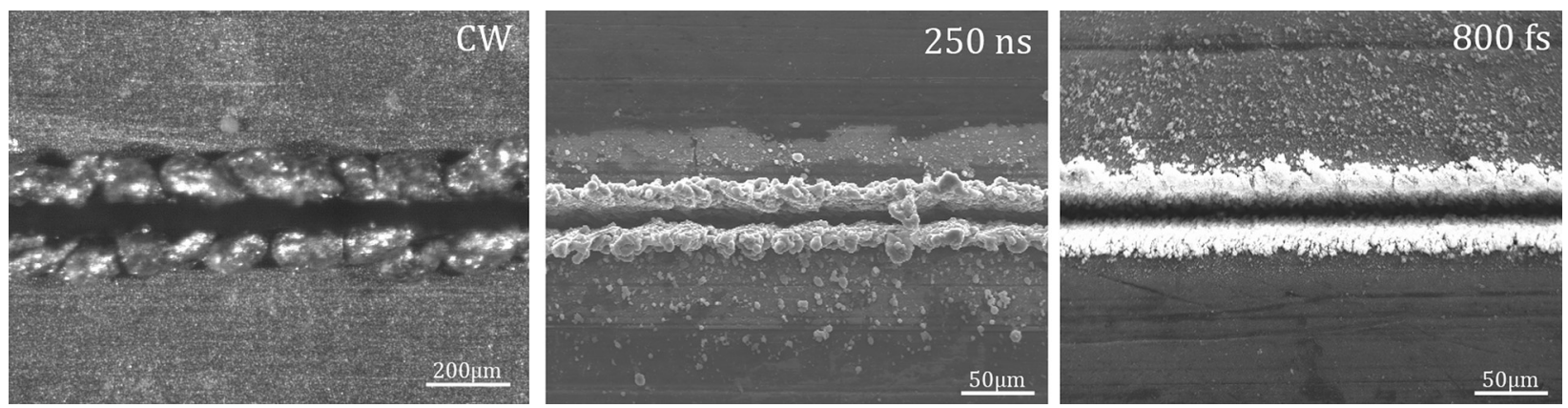

FIG. 3. Dross characteristics in different laser microcutting domains. The bottom view of the cut kerf obtained with CW laser exhibits large amount of dross attached to the exit side. The top view of cut kerf obtained with the ns-pulsed laser shows reduced amount of dross deposited both inside and outside of the kerf. The top view of the cut kerf belonging to the fs-pulsed laser exhibits powderous residue and cleaner kerf. 

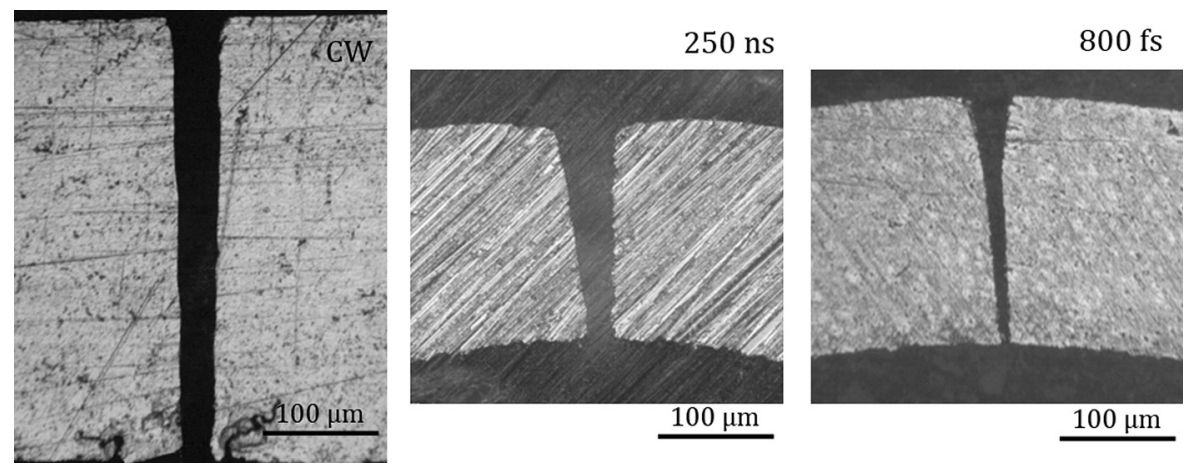

FIG. 4. Kerf characteristics in different laser microcutting domains. The cut kerf obtained with CW laser shows low taper and straight walls. The cut kerf belonging to ns-pulsed laser was fully opened only after the chemical etching and shows larger taper straight walls. The fs-pulsed laser generates a kerf much smaller in size and characterized by two different regions of taper and nonstraight walls.

geometry was reproduced with high precision with slight deviations from the design geometry. Intentionally, no action was taken in the experimentation to compensate differences between the actual and the ideal strut dimensions in laser cutting due to kerf width. The stent mesh cut with the $\mathrm{CW}$ laser showed high amount of spatter attached to the bottom surface of the cut sheet, whereas the scrap pieces could be eliminated by mechanical intervention. The stent cut with the ns-pulsed laser system produced dross that adhered on top of the tube surface, which also closed the kerf. In this case, scrap separation was not possible by means of mechanical intervention. Overall, the stent cut with fs-pulsed system showed no dross on the tube surface, and the scrap pieces could be very easily removed by mechanical intervention. The close up images in Fig. 6 show the cut quality in detail. Large dross droplets with diameters ranging around $50-100 \mu \mathrm{m}$ are present. Such droplets take much smaller dimension in the case of ns-pulsed cutting conditions and exhibit rough stent walls as well as material deposit on the surface. The material residue takes submicrometric size in the case of fs-pulsed laser. Although this powderous residue is not a redeposited molten layer, cleaning in ultrasonic bath immersed in acetone was not sufficient to clean the stent. For all cases, the need for post cleaning process by means of chemical etching was observed to be necessary.

Figures 7 and 8 show the stent meshes and cutting edges in details after chemical etching respectively. The dross cleaning of $\mathrm{CW}$ laser cut stent mesh was possible only after $180 \mathrm{~s}$ of total immersion time inside the $95 \%$ ethanol and $5 \%$ $\mathrm{HNO}_{3}$ etchant. This is the consequence of large amount of dross and smaller surface area for chemical etching to take effect. Accordingly, the etching of the dross follows a similar rate to the etching of the stent body. Resultantly, the stent

TABLE IV. Measured kerf width and taper angles belonging to different laser microcutting conditions.

\begin{tabular}{lccr}
\hline \hline Laser type & CW & ns-pulsed & fs-pulsed \\
\hline Kerf width at top, $\mathrm{w}_{\text {top }}$ & $50.1 \mu \mathrm{m}$ & $54.8 \mu \mathrm{m}$ & $41.8 \mu \mathrm{m}$ \\
Kerf width at bottom, $\mathrm{w}_{\text {bottom }}$ & $26.8 \mu \mathrm{m}$ & $28.9 \mu \mathrm{m}$ & $10.3 \mu \mathrm{m}$ \\
Taper, $\theta$ & $0.21^{\circ}$ & $0.43^{\circ}$ & $0.43^{\circ}$ \\
\hline \hline
\end{tabular}

geometry is altered drastically, with reduced mesh size and stent thickness. This requires very large compensation in the tool trajectory prior to laser microcutting, which can only resolve the reduction in mesh size, whereas stent thickness can be compensated only by using thicker material. On the other hand, the stent surface shows high quality and smoothened edges due to prolonged etching duration.

On the contrary, the chemical etching of the stent realized with ns-pulsed laser system could be completed after $10 \mathrm{~s}$ of immersion in the $90 \%$ ethanol and $10 \% \mathrm{HNO}_{3}$ etchant. The etching allowed kerf opening, scrap separation, and cleaning of the dross on the surface. Moreover, the geometrical precision was maintained and stent body was not etched excessively. However, the resulting stent wall surface quality was not sufficient for implant quality. Further chemical and/or electrochemical polishing is required to improve stent wall quality.

The stent cut with the fs-pulsed system showed the right balance between surface quality and geometrical integrity after chemical etching. After $10 \mathrm{~s}$ of immersion in the $95 \%$ ethanol and $5 \% \mathrm{HNO}_{3}$ solution, the powderous residue was completely removed. The underlying stent wall was smooth and did not require any other postprocessing step. This emphasizes the fact that cleaner laser cutting process allows easier cleaning operation, with reduced duration and maintaining the mesh geometry.

Quantitative measures regarding the stent wall surface quality are represented in Fig. 9. Measurements show that all cutting conditions result in similar $R_{a}$ values higher than $1 \mu \mathrm{m}$, which does not justify the differences observed in the SEM images. $\mathrm{R}_{\mathrm{q}}$ parameter also follows a similar trend. As a matter of fact $R_{z}$ parameter fits much better with the observed trend. A very high value of $R_{\mathrm{Z}}$ is present on the stent wall realized by the CW laser $\left(R_{z}=6.07 \mu \mathrm{m}\right)$. The value of this parameter decreases moving toward ns-pulsed $\left(\mathrm{R}_{\mathrm{z}}=4.56 \mu \mathrm{m}\right)$ and fs-pulsed $\left(\mathrm{R}_{\mathrm{z}}=1.41 \mu \mathrm{m}\right)$ sources. The surface roughness parameters of the chemically etched stents quantify the observed improvement. Both CW and fs-pulsed microcutting conditions exhibited good surface quality, which is confirmed with the observed $R_{a}$ values of $0.56 \mu \mathrm{m}$ and $0.62 \mu \mathrm{m}$, respectively. However, $R_{z}$ parameter depicts absence of large peaks and valleys on the surface in the case of stent realized with 

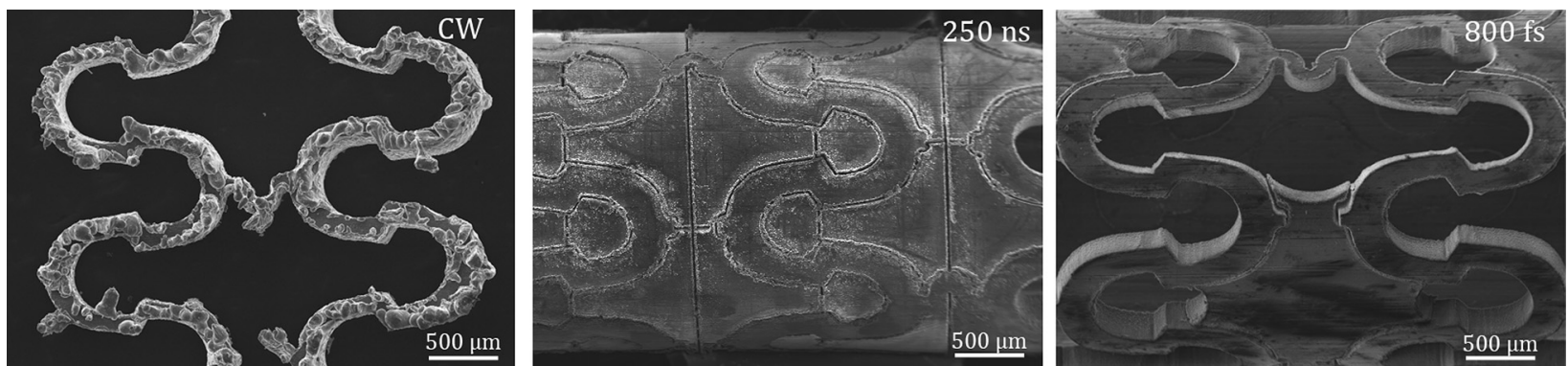

FIG. 5. Stents after laser cutting with different systems. The stent mesh cut on a plate with the CW laser is shown from the bottom side, exhibiting large amount of adhered dross. The stent realized with the ns-pulsed laser shows dross all around the cut kerf and tube. The stent realized with the fs-pulsed laser shows powderous residue attached to kerf.
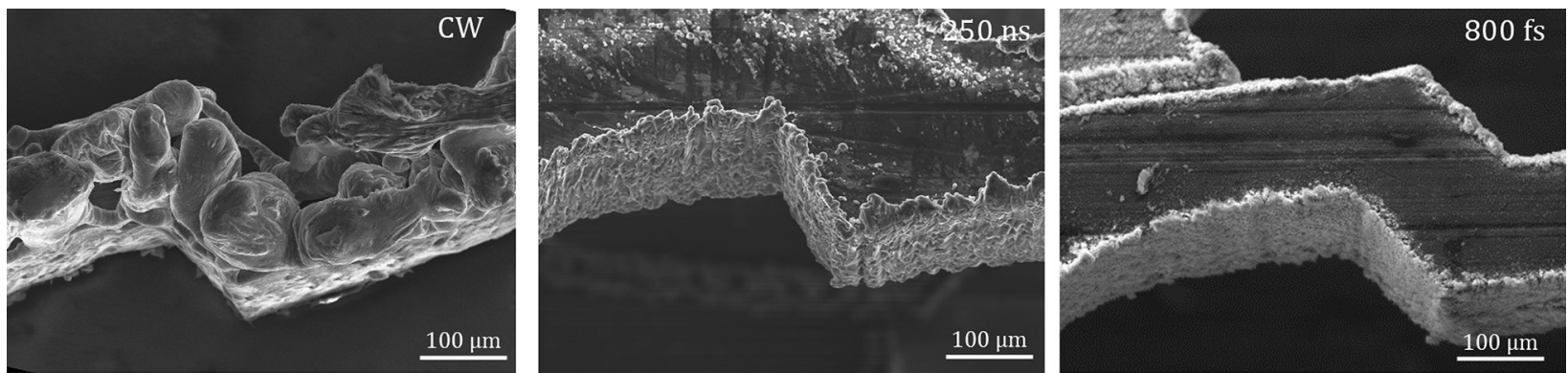

Fig. 6. Details of cutting edge belonging to different laser systems. Cutting edge of CW shows large droplets attached to the bottom. Cutting edge of the ns-pulsed laser shows small droplets of molten material attached to the surface. The dimension of the material residue decreases to submicron level in fs-pulsed cutting conditions.
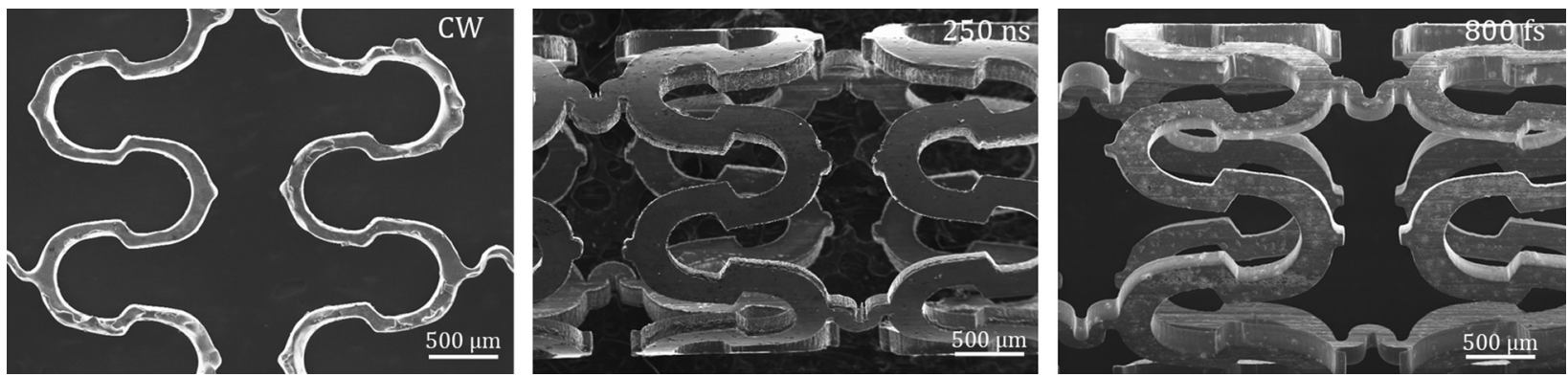

FIG. 7. Stents after chemical etching. Stent mesh on plate realized with CW laser shows no dross with the expense of heavy reduction in size. Chemical etching removes the dross effectively in ns- and fs-pulsed laser cut stents without significant dimensional reduction.
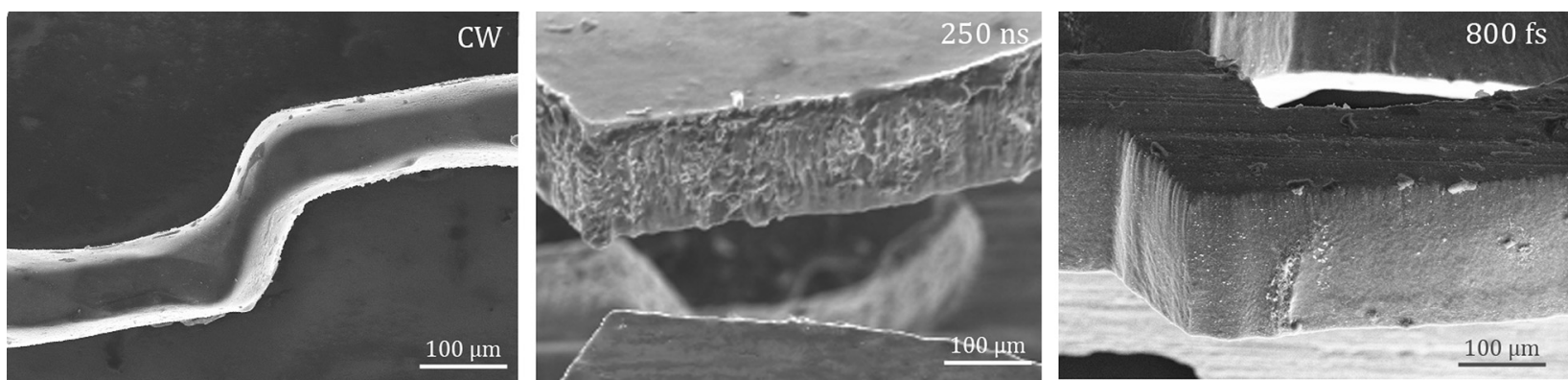

Fig. 8. Details of cutting edge after chemical etching belonging to different laser systems. A very smooth surface as well as rounded edges is observed on the stent mesh cut with the CW system. Chemical etching improves surface wall quality after ns-pulsed cutting; however further processing may be required. Chemical etching of the stent cut with fs-pulsed system results in exceptional surface quality and integrity. 


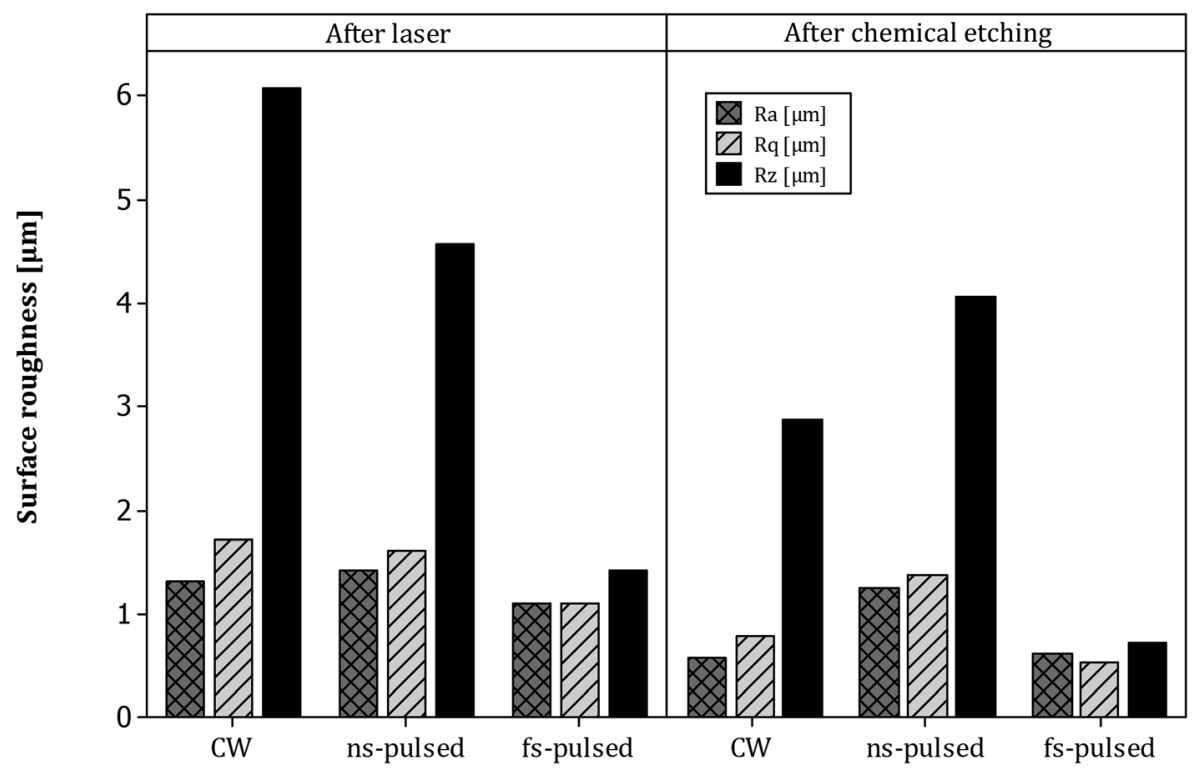

FIG. 9. Surface roughness of the stent walls after laser cutting and consecutive chemical etching. Main surface roughness parameters $R_{a}$, $R_{q}$, and $R_{z}$ are reported for all three cutting conditions and their corresponding chemical etching conditions.

the fs-pulsed system $\left(R_{z}=0.72 \mu \mathrm{m}\right)$. On the other hand, the stent cut with the $C W$ system shows still a large $R_{z}$ value after chemical etching due to the remaining craters and traces of dross $\left(\mathrm{R}_{\mathrm{z}}=2.88 \mu \mathrm{m}\right)$. The ns-pulsed laser system shows worst surface quality after chemical etching $\left(\mathrm{R}_{\mathrm{a}}=1.26 \mu \mathrm{m}\right.$ and $\mathrm{R}_{\mathrm{z}}=4.05 \mu \mathrm{m}$ ), although further chemical etching can be applied to improve quality with a compromise of reduction in stent body.

In order to better quantify the productivity aspect, the process cycle time to realize a stent was calculated using the proposed laser cutting and chemical etching parameters. The process cycle time consisted of five components:

(1) Laser cutting time $\left(t_{\text {cut }}\right)$ : The calculated cutting time using the cutting speed (v) and total stent trajectory $(293.77 \mathrm{~mm})$.

(2) Ultrasonic cleaning times in acetone bath $\left(t_{U S}\right.$ and $t_{U S}$ 2): The time required for cleaning the stent after laser

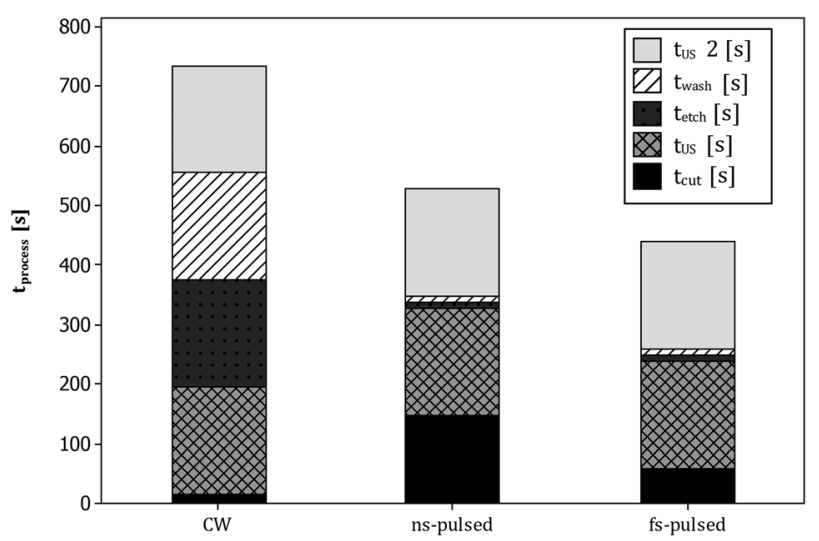

FIG. 10. Process cycle times for realizing stents using CW, ns- and fs-pulsed lasers in the production cycles. The different components are summed up to calculate the total process time, where the cutting time contributes much less compared to the postprocessing steps. cutting for the first time $\left(\mathrm{t}_{\mathrm{US}}\right)$ and after chemical etching for the second time $\left(t_{U S} 2\right)$. For both cases and all microcutting conditions, the cleaning duration was fixed as $180 \mathrm{~s}$.

(3) Chemical etching time $\left(t_{\text {etch }}\right)$ : The total immersion time in the etchant for dross removal. Chemical etching was applied in $10 \mathrm{~s}$ of intervals and the chemical etching time corresponds to the sum for the given laser microcutting condition.

(4) Washing time $\left(t_{\text {wash }}\right)$ : Each chemical etching step was accompanied by $10 \mathrm{~s}$ of immersion in water. Washing time corresponds to the sum of the wash steps for the given laser microcutting condition and is equal to the chemical etching time.

Figure 10 shows each component of the process cycle time for every single laser microcutting condition. It can be seen that the laser microcutting duration corresponds to a very limited amount of time within the whole cycle. The process cycle time highly depends on the ease of cleaning, therefore the laser cutting quality. The highest cycle time was present for the fastest laser cutting conditions given by the CW laser at $12 \mathrm{~min} 14 \mathrm{~s}$. The cycle times for stent production using ns-pulsed and fs-pulsed lasers were $8 \min 47 \mathrm{~s}$ and $7 \mathrm{~min} 18 \mathrm{~s}$, respectively. Although the calculations are only indicative, they demonstrate that the higher laser cutting speed does not necessarily correspond to higher productivity, as the cut quality is the determining factor for the whole cleaning procedure.

Regarding the cutting and postprocessing, Table V summarizes the findings of the comparative study in a qualitative manner. In addition to the technical aspects, another important factor regarding the industrial viability is the capital and maintenance costs regarding the used laser source. As reported indicatively in Table $\mathrm{V}$, the best manufacturing 
TABLE V. Summary of the outcomes of the comparative study.

\begin{tabular}{lccc}
\hline \hline Laser type & CW & ns-pulsed & fs-pulsed \\
\hline Cutting speed & High & Low & Medium \\
Cut quality & Low & Medium & High \\
Postprocess & Difficult & Manageable & Easy \\
Geometrical compensation & High & Low & Low \\
for postprocessing & & & \\
Investment & Medium & Low & High \\
\hline \hline
\end{tabular}

quality is obtained with the highest capital cost in the case fs-pulsed laser. The lowest capital cost belongs to the ns-pulsed laser that showed a margin of improvement with further postprocessing. The cost of the laser system also represents the complex nature of the laser source, which in fact reflects to the maintenance difficulties and related costs. Although technological feasibility plays the key role in the manufacturing of biodegradable $\mathrm{Mg}$ stents, for wider industrial diffusion and reduced production costs, the capital and maintenance costs of ultrafast laser systems should reduce.

\section{CONCLUSIONS}

The present paper reported a comparative study in laser microcutting of AZ31 alloy for manufacturing biodegradable stents. The work aimed to demonstrate the differences in microcutting domains governed by the pulse duration parameter. Because the pulse duration is a laser source characteristic rather than a control parameter, the paper focused on representative laser microcutting conditions using $\mathrm{CW}$, ns- and fs-pulsed lasers. This decision is also a consequence of the small process parameter window of laser microcutting process within a given pulse duration domain. The laser microcutting was evaluated with the consecutive chemical etching process as the finishing operation. The results show a strict correlation between the dross characteristics and the efficacy of the chemical etching operation. Fs-pulsed laser cutting allowed maintaining stent geometry, avoiding excessive etching of the stent body during dross elimination. On the other hand, the very fast $\mathrm{CW}$ microcutting generated high amount of melt deposit, which was hard to remove and resulted in excessive reduction of stent geometry. Stent quality was evaluated on the cut edge of the stent wall by means of focus variation microscopy. The measurements depict the improvement provided by the optimal fs-pulsed laser microcutting and gentle chemical etching in terms of low surface roughness parameters. However, this work confirms the difficulty in defining the surface quality of a stent, and the importance of regulations regarding surface measurement of biomedical devices. In this work, $\mathrm{R}_{\mathrm{z}}$ was found to adequately represent the observed cutting quality in the SEM images. In literature, both linear and areal surface roughness parameters are used based on measurement acquired by devices of different nature (i.e., confocal microscopy, white light interferometry, and atomic force microscopy). Therefore, a quantitative comparison of the measured roughness values seems to be difficult. The identification and standardization of surface quality analysis of stents remains as an open question for both research and industrial perspectives. The comparative study concluded that $\mathrm{CW}$ microcutting with the highest cutting speed did not correspond to the highest productivity. The fs-pulsed microcutting did not eliminate the need to postprocessing, but it allowed reducing production cycle time by rendering the postprocessing stage fast and easy. Further implications from this work regarding the laser microcutting of different metallic materials can be made only to a limited extent. Although the material removal mechanisms remain the same for most of the metallic materials, the final quality depends highly on the material properties. Similar comparative studies can be useful to determine the optimal laser source for different case scenarios in stent manufacturing. Such studies would benefit from the comparison of different laser wavelengths and pulse shapes that were not considered in this work.

\section{ACKNOWLEDGMENTS}

The authors acknowledge the financial support from Fondazione CaRiTRO for partially funding the research under Grant No. 2011.0250. The authors also acknowledge the support from IPG Italy for their availability to use the CW laser system, and Rofin Baasel Lasertech Gmbh for their availability to use the fs-pulsed laser system. The authors declare that they have no competing interests.

${ }^{1}$ G. Mani, M. D. Feldman, D. Patel, and C. M. Agrawal, Biomaterials 28, 1689 (2007).

${ }^{2}$ B. O'Brien and W. Carroll, Acta Biomater. 5, 945 (2009).

${ }^{3}$ H. Hermawan, D. Dubé, and D. Mantovani, Acta Biomater. 6, 1693 (2010).

${ }^{4}$ M. Moravej and D. Mantovani, Int. J. Mol. Sci. 12, 4250 (2011).

${ }^{5}$ F. Stefano, G. Qiang, V. Maurizio, V. Gianmarco, G. Dario, F. Migliavacca, L. Petrini, and S. Trasatti, Revista Matéria 15, 96 (2010).

${ }^{6}$ G. Wang, S. Ge, Y. Shen, H. Wang, Q. Dong, Q. Zhang, J. Gao, and Y. Wang, Mater. Sci. Eng. C 32, 2190 (2012).

${ }^{7}$ J. Geis-Gerstorfer, C. Schille, E. Schweizer, F. Rupp, L. Scheideler, H.-P. Reichel, N. Hort, A. Nolte, and H.-P. Wendel, Mater. Sci. Eng. B 176, 1761 (2011).

${ }^{8}$ M. Alvarez-Lopez, M. D. Pereda, J. A. del Valle, M. Fernandez-Lorenzo, M. C. Garcia-Alonso, O. A. Ruano, and M. L. Escudero, Acta Biomater. 6, 1763 (2010).

${ }^{9}$ Q. Ge, D. Dellasega, A. G. Demir, and M. Vedani, Acta Biomater. 9, 8604 (2013).

${ }^{10} \mathrm{H}$. Hornberger, S. Virtanen, and A. R. Boccaccini, Acta Biomaterialia 8, 2442 (2012).

${ }^{11}$ W. Wu, L. Petrini, D. Gastaldi, T. Villa, M. Vedani, E. Lesma, B. Previtali, and F. Migliavacca, Ann. Biomed. Eng. 38, 2829 (2010).

${ }^{12}$ W. Wu, D. Gastaldi, K. Yang, L. Tan, L. Petrini, and F. Migliavacca, Mater. Sci. Eng. B 176, 1733 (2011).

${ }^{13}$ W. M. Steen, Laser Material Processing, 3rd ed. (Springer-Verlag, London, 2003).

${ }^{14}$ K. F. Kleine, B. Whitney, and K. G. Watkins, "Use of fiber lasers for micro cutting applications in the medical device industry," in Proceedings of ICALEO 2002, edited by E. Beyer, R. Patel, Y. L. Yao, and A. Ostendorf, Scottsdale, AZ, 2002, pp. 1-10.

${ }^{15}$ M. Baumeister, K. Dickmann, and T. Hoult, Appl. Phys. A 85, 121 (2006).

${ }^{16}$ H. Meng, J. Liao, Y. Zhou, and Q. Zhang, Opt. Laser Technol. 41, 300 (2009).

${ }^{17}$ N. Muhammad, D. Whitehead, A. Boor, and L. Li, J. Mater. Process. Technol. 210, 2261 (2010)

${ }^{18}$ B. N. Chichkov, C. Momma, S. Nolte, F. von Alvensleben, and A. Tünnermann, Appl. Phys. A 63, 109 (1996). 
${ }^{19}$ W. Schultz, E. Eppelt, and R. Poprawe, J. Laser Applicat. 25, 012006 (2013).

${ }^{20}$ J. Cheng, C. Liu, S. Shang, D. Liu, W. Perrie, G. Dearden, and K. Watkins, Opt. Laser Technol. 46, 88 (2013).

${ }^{21}$ Y. P. Kathuria, J. Mater. Process. Technol. 170, 545 (2005).

${ }^{22}$ A. Raval, A. Choubey, C. Engineer, and D. Kothwala, Mater. Sci. Eng. A 386, 331 (2004).

${ }^{23}$ A. G. Demir, B. Previtali, and C. A. Biffi, Adv. Mater. Sci. Eng. 2013, 692635, (2013).

${ }^{24}$ N. Muhammad, D. Whitehead, A. Boor, W. Oppenlander, Z. Liu, and L. Li, Appl. Phys. A 106, 607 (2012).

${ }^{25}$ N. Muhammad and L. Li, Appl. Phys. A 107, 849 (2012).

${ }^{26}$ A. G. Demir, B. Previtali, Q. Ge, M. Vedani, W. Wu, F. Migliavacca, L. Petrini, C. A. Biffi, and M. Bestetti, "Biodegradable magnesium coronary stents: material, design and fabrication,” Int. J. Comput. Integr. Manuf. (published online).

${ }^{27}$ E. Galvin, M. M. Morshed, C. Cummins, S. Daniels, C. Lally, and B. MacDonald, Plasma Chem. Plasma Process 33, 1137 (2013).

${ }^{28}$ R. Waksman, R. Pakala, P. K. Kuchulakanti, R. Baffour, D. Hellinga, R. Seabron, F. O. Tio, E. Wittchow, S. Hartwig, C. Harder, R. Rohde, B. Heublein, A. Andreae, K.-H. Waldmann, and A. Haverich, Catheter. Cardiovasc. Interv. 68, 607 (2006).

${ }^{29}$ P. Zartner, R. Cesnjevar, H. Singer, and M. Weyand, Catheter. Cardiovasc. Interv. 66, 590 (2005).

${ }^{30}$ R. Erbel et al., Lancet 369, 1869 (2007).

${ }^{31}$ J. Sun and J. P. Longtin, J. Appl. Phys. 89, 8219 (2001).

${ }^{32}$ C. Li, S. R. Vatsya, and S. K. Nikumb, J. Laser Applicat. 19, 26 (2007). 